\title{
The effect of cryotherapy on chemotherapy induced oral mucositis in Egyptian cancer patients: A randomized controlled trial
}

\author{
Hanan Mohamed Mohamed Soliman* \\ Faculty of Nursing, Mansoura University, Medical-Surgical Nursing Department, El mansoura City, Egypt
}

Received: June 10, 2019

DOI: $10.5430 /$ jnep.v9n11p63
Accepted: August 4, 2019

Online Published: August 26, 2019

URL: https://doi.org/10.5430/jnep.v9n11p63

\begin{abstract}
Background and objective: Oral Mucositis (OM) is a common adverse side-effect caused by cancer treatments (chemotherapy and/or radiotherapy). And can lead to mucosa toxicity. Patients with OM may experience extreme pain and may not be able to eat, drink and talk and, as a result, their quality of life is impaired. Treatment and prevention of OM in adult patients treated with chemotherapy are challenging issues for health care professionals. The aim of this study was to evaluate the effect of cryotherapy on incidence and severity of chemotherapy-induced OM and OM related pain in patients treated with combined chemotherapy (Fluorouracil and Leucovorin).

Methods: This study a randomized controlled trial with a random assignment to cryotherapy and control groups. The study was conducted on 40 cancer patients who underwent chemotherapy. The 20 patients in cryotherapy group were received instructions for sucking ice cubes in their mouth for five minutes before, during and shortly after chemotherapy. The 20 patients in control group received routine care. OM and pain severity were evaluated at 7th, 14th and 21 st days of the study after chemotherapy using WHO Mucositis grading and-Numeric Pain Rating Scale.

Results: In the majority of patients in cryotherapy group, oral Mucositis was not detected (Grade 0) at 7th, 14th and 21st days similarly incidence of grade 1 and 2 of OM in cryotherapy group significantly lowered when compared with control group where $p<.001$. During the study period, patients in the control group exhibit a significantly higher level of oral discomfort $(p=.001)$. Conclusions: Oral cryotherapy due to its easy administration, tolerability and lack of adverse effects which makes it a very important method for decreasing the severity and incidence of OM and OM associated pain. The oncology nurses have a pivotal role in the application and success of cryotherapy.
\end{abstract}

Key Words: Cryotherapy, Chemotherapy, Ice, Mucositis, Pain

\section{INTRODUCTION}

Oral Mucositis $(\mathrm{OM})$ is one of the commonest complications of cancer therapy (chemotherapy and/or radiotherapy). OM can be defined as inflammation of the mucosa of mouth, and is clinically evaluated by the appearance of ulcerations. ${ }^{[1]}$ Basically, oral mucosa and saliva secretion considered a nor- mal protective barrier against invasion by microorganisms. However, these barriers may be damaged in cancer patients receiving chemotherapy. Therefore, OM occurs due to disruption in oral mucosa as a result of side effects to cancer treatment by chemotherapeutic agents or radiation therapy. It could also be painful, temporarily impair with normal eating

\footnotetext{
*Correspondence: Hanan Mohamed Mohamed Soliman; Email: Hanansoliman697@ymail.com; Address: Faculty of Nursing, Mansoura University, Medical-Surgical Nursing Department, El mansoura City, Egypt.
} 
or oral intake and may become infected, sometimes resulting in general infection. ${ }^{[2,3]} \mathrm{OM}$ one of the common complications of cancer treatment, that's manifested in eightieth of patients with head and neck cancers undergoing radiation and a valuable range of patients receiving chemotherapeutical agents. ${ }^{[4,5]}$ Severity and frequency of OM are basically dependent up on the type, dose and duration of chemotherapeutic agents used in cancer treatment. ${ }^{[6]}$ In this sense, bone marrow-suppressing (myeloablative) chemotherapy is associated with a mucositis risk of $60 \%-100 \% \cdot .^{[4,6,7]}$ Whereas the combination of chemo and radiotherapy implies a risk of just about $100 \% .{ }^{[2]}$ The clinical manifestations of OM appear 4-5 days once the beginning of chemotherapy, with the detection of erythematous areas within the mouth. After 7-10 days of chemotherapy ulcers begin to develop; these bit by bit grow size, and have a tendency to merge, forming massive ulcerous zones. ${ }^{[5,7]}$ These lesions are terribly painful, cause swallowing difficulties and take about 14 days to heal once chemotherapy has been suspended. ${ }^{[2,5]}$ Variety of OM classification and staging systems are delineated. The foremost wide used is that planned by the World Health Organization (WHO) (see Table 1). ${ }^{[8]}$

Table 1. World Health Organization Mucositis grades

\begin{tabular}{ll}
\hline Description & Grade \\
\hline None & 0 \\
$\begin{array}{l}\text { Erythema, painful ulcers, mild sore throat } \\
\text { Painful erythema, painful ulcers, edema of the oral } \\
\text { mucosa, but able to eat solid food }\end{array}$ & 1 \\
$\begin{array}{l}\text { Painful erythema, painful ulcers, painful edema of the } \\
\text { oral mucosa that interferes with eating solid food }\end{array}$ & 3 \\
$\begin{array}{l}\text { Need for parenteral or enteric support due to very } \\
\text { severe stomatitis }\end{array}$ & 4 \\
\hline
\end{tabular}

Treatment of OM is especially built on supportive therapies, i.e., oral hygiene, consumption of adequate liquids, and application of mouth washes. Patients are suggested to avoid alcohol, citrus fruits, and hot foods. Supporting studies have introduced varied substances and agents as effective medications for inhibiting or limiting signs and symptoms of OM. Interestingly, cryotherapy has been studied as an effective intervention in OM prevention to completely different chemotherapy regimens. The results showed cryotherapy to be effective in prevention interference of development of $\mathrm{OM}$ once used with chemotherapeutical agents having a short plasma half-life, like bolus doses of 5-fluorouracil and melphalan. ${ }^{[9]}$ Worthington and associate confirmed that ice ships reduces formation of mucositis by five hundredth in all patients treated by chemotherapeutic medications. ${ }^{[10]}$ Additionally, there are many studies indicated the effectiveness of cryotherapy in reducing chemotherapy-induced OM. ${ }^{[11-15]}$
Anti-inflammatories also play a role in the treatment of stomatitis; this could contain simple washes with Chamomile tea which has antinflamatory properties. The use of benzydamine which has multiple action as antinflammatory, antimicrobial analgesic and cytoprotectant actions has been evaluated in small trial and has been verified to have significant effect. Antibiotics and antifungal of chewable pastilles are an option to treat OM. ${ }^{[16]}$

Various modalities have been used to decrease chemotherapy side effects. Cryotherapy is one among these modalities. Cryotherapy the foremost standard and simple-to-use preventive technique, for 5-FU-based bolus treatment, and seems to possess implications for different chemotherapy regimens similarly, like, edatrexate and melphalan. ${ }^{[17]}$ Consistent with the [ESMO Working Group] results, 30 min oral cryotherapy is often recommended for reducing $\mathrm{OM}$ in patients treated by bolus 5-FU chemotherapy. ${ }^{[7]}$ Oral cryotherapy is that the applying of ice cubes or ice-chips to the mouth.

Oral cryotherapy for chemotherapy-associated OM wants that patients suck on ice cubes or ice ships pre, during, and post administering of chemotherapeutic agents. ${ }^{[1]}$ The idea behind oral cryotherapy is that ice ships can constrict the blood vessels of the mouth, thus reducing risk of the oral mucosa due to chemotherapeutic medication. ${ }^{[18]}$ supported the findings by ${ }^{[10]}$ Many interventions found to be somewhat useful at preventing or reducing the severity of mucositis induced by cancer treatment. But the strength of the findings was variable and also the advantage of cryotherapy is also specific certainly to cancer types and drug. Within the nursing literature associated with mucositis management, standard care of mucositis prevention is quite limited. Yet, because the nurses need to have a central position, the nurses ought to have a pivotal role in the treatment and prevention of OM. The current research study was conducted to investigate the effect of cryotherapy on severity and incidence of $\mathrm{OM}$ associated with chemotherapy and OM related pain, in patients treated with combined chemotherapy (fluorouracil and leucovorin).

\subsection{Need for the study}

Global cancer rates may increase by $50 \%$ to 15 million by 2020. World Health Organization estimates that ' 84 ' million individuals will die of cancer between 2005 and 2015. OM is a frequently occurring and debilitating complication of chemotherapy. Consequently OM will result in malnutrition, fluid electrolyte imbalances, and different complications such as infection. In spite of large choice of prophylactic agents offered, there's very little consistency among institutions, and many commonly used interventions are not evidence-based. As well as, however cryotherapy has many advantages in 
preventing mucositis, but there are some deficiencies in these experimental studies, such as a small number of supportive studies, which were designed specifically for chemotherapy, for the above reasons, the researcher motivated to undertake this study. As ice cubes may be prepared promptly available and cheaper, individuals undergoing chemotherapy might effectively use this in their due course of therapy. Therefore, the current research study was conducted to investigate the effect of cryotherapy on severity and incidence of OM associated with chemotherapy and OM related pain, in patients treated with combined chemotherapy (fluorouracil and leucovorin). "Not everything that is faced can be changed. But nothing can be changed until it is faced." James Baldwin

\section{RESEARCH METHODS}

\subsection{Aim}

The aim of this study is to evaluate the effect of cryotherapy on incidence and severity of chemotherapy-induced OM and OM related pain in patients treated with combined chemotherapy (Fluorouracil and Leucovorin).

\subsection{The hypothesis}

The following research hypothesis formulated in an attempt to achieve the aim of the study: $\mathrm{H}$ : Patients who receive cryotherapy (Cryo group) will have less incidence and severity in OM and OM related pain compared to patients who do not receive it (control group).

\subsection{Design, sample, and setting}

The research design of this study was a randomized, controlled clinical trial with a random assignment to study group $(n=20)$ receiving oral cryotherapy (cryo-group) or control group $(n=20)$ receiving routine care. Calculating sample size through Clin calc.com sample size calculator soft ware, at $1 \%$ error (99.0\% significance) and $10.0 \beta$ error $(90.0 \%$ power of the study), assuming average score of physician judged mucositis grading among intervention group is 0.95 \pm 0.13 at 14th day and in control group it is $1.2 \pm 0.20$ (Kakoei et al., 2013). The calculated sample size is 19 in each group. We can add $5 \%$ for better data and follow up drop, so the field study sample will be 20 in each group.

For randomization, 1st 5 patients were categorized to cryo group and the next 5 patients to control group till forty patients were recruited. For homogeneity purposes, the questionnaire was filled in before administration of oral cryotherapy. All sample were Egyptians, cancer type (all were colon, rectal and gastric), course of therapy (all were within the first course) and also the number of patients in every group ( $n=20$ for every group). The current research study was conducted from April 2017-March 2018 to cancer patients

Published by Sciedu Press received out-patient chemotherapy at oncology hospital affiliated with Mansoura University Hospitals in Mansoura City, Egypt and Mit Ghamr Oncology Center, Egypt. All of forty patients diagnosed with colon, rectal and gastric cancer were treated by combination chemotherapy with MAYO. The Mayo protocol of treatment involved 5-FU at a dose of 425 $\mathrm{mg} / \mathrm{m}^{2}$ and Leucovorin at a dose of twenty five $\mathrm{mg} / \mathrm{m}^{2}$ for 5 consecutive days, to be repeated every three week.

Inclusion criteria include the following: Adult aged from 20 to 60 years diagnosed of colon, rectal and gastric cancer, receiving intravenous 5-fluorouracil and leucovorin as a first initial course, having no dental disease.

Exclusion criteria include: Patients with head-neck cancer, patients who previously underwent first course of chemotherapy, patients with dental problems, antineoplastic drugs with a half-life of $30 \mathrm{~min}$ or more, patients who receive more than one combination chemotherapy. ${ }^{[19,20]}$

\subsection{Operational definitions}

\subsubsection{Oral mucositis}

Refers to the soreness and erythematic of oral mucosa occurring as a complications result of chemotherapy which might be evaluated using WHO scale for assessing Mucositis.

\subsubsection{Oral cryotherapy}

In the present study oral cryotherapy refers holding ice cubes within the mouth for 15-20 minutes.

\subsection{Instruments}

Three Tools used for data collection in the current study as follows: 1-Socio-demographic and Medical Data Form, 2WHO Mucositis Scale (see Table 1) and 3-Numeric Pain Rating Scale.

\subsubsection{Socio-demographic and Medical Data Form}

This tool was developed by the researcher once comprehensive review of relevant literature of OM and chemotherapy. The elements of this tool as follows: the age and sex of the patient, general diseases, prosthetic device in oral cavity, smoking and drinking habits, caries, periodontic diseases, oral hygien, buccal cavity status additionally, taste, unhealthy dietary habits, daily water intake, gastrointestinal problems as, diarrhea and vomit, was comprised of demographic data, factors that have an effect on OM, disease-related characteristic and questions releated the variables that may result in the formation of OM post chemotherapeutic agent. ${ }^{[20-22]}$

\subsubsection{World Health Organization Mucositis scale}

World Health Organization (WHO) Mucositis Scale was one amongst the best developed scale that integrates all subjective and objective criteria. Based mostly clinical examination 
four distinct stages/grades may be known that are given (0) to (4) Mucositis scores. Oral intake is maintained in grade (1) and (2) however compromised in higher grades. ${ }^{\text {[23] }}$ The validity of the WHO Mucositis Scale has been developed in many studies. OM were assessed based on the Oral Toxicity Scale of the WHO, that relies on objective and subjective signs and ability to eat solids and liquids. The WHO scale categories mucosa to 4 levels or grades: Grade zero, absence changes discovered in mouth throughout management protocol; Grade I, exhibit of pain and erythematic in mucous membrane, and palate; Grade II, Painful erythema and painful ulcers, having the ability to perform normal eating. Grade III, painful edema, and Grade IV, severe stomatitis, that interferes with eating. Mucositis scale developed by WHO (see Table 1) were designed for Mucositis evaluation. ${ }^{[24]}$ In our study we practice OM assessment, seven, fourteen and twenty one days after chemotherapy. The rational is because of some studies identified that OM developed 5-10 or 7-14 days post chemotherapy which they reduce at intervals 2-3 weeks folowing chemotherapy. ${ }^{[25,26]}$

\subsubsection{Numeric pain rating scale}

Numerical Rating Scale for Pain Intensity (NRSI) is a verbally administered scale that measures pain intensity ("how much pain do you feel right now?"). The NRS can also used to verify pain unpleasantness ("how unpleasant/horrible/yucky is that the pain right now?"). The top points reflect the extremes of the pain sensation., zero $=a b$ sence of pain, ten $=$ worst possible pain, medical members instruct participants to categorize their current pain on a scale of zero ("absence of pain") to ten ("worst possible pain"). According to different clinical studies we can classify pain as mild, moderate, or severe (1-3), (4-6) or (7-10) respectively. Studies of chronic pain patients with completely different conditions have reached varied conclusions regarding the optimum cut points for mild, moderate, and severe pain on the 0-10 NRS, with four or five being the commonest suggested lower limits for moderate pain and seven or eight for severe pain. ${ }^{[27-32]}$ We select a score of four indicators to the lower limit for moderate pain. It is most popular accepted for clinical and administrative use. Validity: Concurrent validity-excellent, highly related to the Visual Analogue Scale (VAS) 3; Face, convergent and divergent validity-excellent, higher than the VAS and McGill Pain form. ${ }^{[12]}$

\subsubsection{Validity and reliability of tools}

The content validity of tool I that was created by the researcher once reviewing of the relevant literature was established by a panel of eight expertise ( 3 oncologists, 2 dentists, and 3 oncology nursing professor) to establish its relevancy and completeness. No modifications were done. Reliability testing was done using split half methods and Cronbach's alpha that measures the degree of reliability for the data collection tools. Each technique showed high reliability of the final version of the tool $(1)$. (Alpha $=.85)$. The remaining two adopted tools II, III, are used as itself with no change and its validity and reliability have been established in many studies. Respectively inter-rater reliability was developed at 0.86 for the Mucositis Scale established by WHO, 0.78 for the Numeric Pain Rating Scale. ${ }^{[12,33]}$

\subsection{Application of cryotherapy}

Specific ice cubes arranged for cryotherapy, the corners that are rounded, its size appropriate for being moved simply within the mouth were used. If the subjects had any prosthetic teeth, they were asked to get rid of them before application of cryotherapy. The patients in a study group instructed to hold \& move ice cubes (cryo group) from five min before, throughout treatment until five min after chemotherapy for a total of twenty - forty five min. Keep enough Ice cubes in the refrigerator of chemotherapy ward before administering chemotherapy to the patient to avoid waiting time between every ice cubes. Cryotherapy was maintained based on the characteristics of the chemotherapy protocol and additionally the duration of infusion. This timeline identified depending on the half-lives of the medication. ${ }^{[12,21,22]}$ Patients were taught of the importance of maintaining the mouth cold. Once the ice cubes dissolved they were replaced by new ones. Oral cryotherapy was used in subjects treated by the MAYO protocol throughout the first 5 days of mucotoxic agent. Oral cryotherapy was used pre, throughout and post the drug infusion. ${ }^{[22]}$ Oral cryotherapy was well-tolerated in addition most of patients clarified that they didn't exhibit any discomfort in keeping ice cubes in their mouth for over than over thirty min. Most of patients indicated that they instructed to maintain the mouth cooled during the cancer therapy.

\subsection{Procedure}

Official written permissions, to conduct the study were obtained from the Research Ethical Committee of college of Nursing Mansoura university and also the Director of the oncology Hospital, Mansoura university, Egypt similarly head nurses. This was achieved after clear clarification of the purpose and nature of the study in addition its expected outcomes. Patients consent for participation in the study was obtained after clarification of the aim of the study and also the confidentiality was assumed. Validity and reliability of tools are established. The data collection started from the first April 2017 up to end of March 2018. A pilot study was conducted on $10 \%$ of study sample (4 patients) to evaluate the developed tools for clarity and relevancy then necessary modification applied. The results of the pilot study are ex- 
cluded from the study. Every patient agrees to participate in the study and fulfilling the inclusion criteria was interviewed separately by the researcher in chemotherapy department of Clinical Oncology Department. The study sample was chosen randomly and divided alternatively into 2 equal groups, study group (1) (cryo-group) and control group (2). In the study group The patient was taught how to prevent oral infection by applying universal oral care guidelines using a soft toothbrush, a mild toothpaste and dental floss two time per day) and suck ice cubes from five min before, during treatment till five min after chemotherapy for a total of twenty to forty five min. The control group instructed about importance of applying standard oral care using a soft toothbrush, a mild toothpaste and dental floss two time per day) and was left to routine hospital care for Mucositis. The researcher filled in the data assessment questionnaire after a personal interview with the study samples before starting the chemotherapy course then the WHO Mucositis Scale was utilized to assess the mouth for Mucositis in patients prior to chemotherapy as well as OM related pain was assessed by third tool. During the current research study, ice chips was used for only one cycle of chemotherapeutic agent. Researcher evaluates mucositis through the 1st cycle of chemotherapy (4 weeks). On an individual basis interview was done to assess OM and pain associated at the first day of the chemotherapy sessions to gather baseline data, 7th day, 14 and at twenty one day of chemotherapy sessions. The comparison were done between 2 groups.

\subsection{Patients right and ethical concerns}

Ethical permission was taken from the Ethics panel of college of Nursing, Mansoura-University to conduct the study. Verbal aproval was obtained from every patient prior his/her inclusion into the study after clarification of the aims of the study. The researcher emphasized that participation is completely voluntary and participants may withdraw from the study at any stage. Confidential, anonymity, privacy, rights, safety of the sample was completely assured from the start of the study.

\subsection{Data analysis}

Data was analyzed by adapting SPSS (Statistical Package for Social Sciences) version fifteen. Descriptive data was presented as number and percent. Comparison between groups was done by Chi-Square test. Wilcoxon singed ranks test was used for comparison within group. $p<.05$ was considered to be statistically significant.

\subsection{Conceptual/theoretical framework}

Pender's health promotion model is a nursing model which enables to predict the health behaviour. The HPM this is used universally for research, education, and practice. This model relies on supporting people acquire better health and identifies factors that affect health behavior. It encourages health care provider to change the patient behavior. The usage of the HBM and working collaboratively with the client, the nurse can assist the client in converting behaviors to achieve a healthy lifestyle. So the aim of the HBM is to prevent illness as well as to improve well being. The HBM also can help nurses to be knowledgeable about determinants of health behaviors as a basis for behavioral modifications. ${ }^{[34]}$

\section{RESULTS}

All the forty patients completed the study period and had no lapse throughout the study. A complete of forty patients were enrolled. Mean ages of the patients in the control and cryotherapy groups were equal $49.1 \pm 15.4$ and $42.9 \pm 14.9$ years, respectively. The study groups had no significance differences as regards age, sex, education level as shown in Table 2. The majority of both control and cryotherapy group were female (75\% \& 60\% respectively). Only 55\% of control group read and writes and three forth of control group was house wife. It is also observed that ,most of the subjects in cryo and control group were married (85\% \& 80\% respectively).

When considering the effect of oral cryotherapy on OM, Table 3 and Figure 1 clarified that, there was a highly statistically significant differences in incidence \& severity of OM between cryotherapy \& control group. On 7th, 14th and 21st day where $p$ value $<.001 * *$. At the baseline Mucositis assessment, according to WHO Mucositis grading all study sample free from OM at the beginning of study. On the seven day of chemotherapy $45 \%$ of cryotherapy patients were free from (OM) (G0)compared with $0 \%$ in control group which was highly statistically significant $p$ value $<.001 * *$. However, OM (G1) was discovered in $55 \%$ of cryotherapy \& control group as the same. Additionally, cryotherapy patients was free from ( $\mathrm{G} 2, \mathrm{G} 3$ \& G4) OM while control group constitute (30\%, 15\%, \& $0 \%$ respectively). On the 14 th day (G0) OM was detected in $55 \%$ of cryotherapy patients compared to $0 \%$ of the control patients. And G1 was found in $45 \%$ of cryotherapy group compared to $40 \%$ in control group. Although G2. G3 \& G4 OM not observed in cryotherapy group, it was found in control group as $45 \%, 15 \%$ \& $0 \%$ respectively. So there was a highly statistically significant differences between cryotherapy \& control group in incidence and severity of OM where $p<.001$. 
Table 2. Patient characteristics of both cryotherapy and control groups $(n=40)$

\begin{tabular}{|c|c|c|c|c|}
\hline & $\begin{array}{l}\text { Cryotherapy Group } \\
(\mathrm{n}=\mathbf{2 0})\end{array}$ & $\begin{array}{l}\text { Control Group } \\
(\mathrm{n}=\mathbf{2 0 )}\end{array}$ & $\chi^{2}$ & $p$ value \\
\hline \multicolumn{5}{|l|}{ Sex } \\
\hline Male & $8(40 \%)$ & $5(25 \%)$ & \multirow{2}{*}{1.026} & \multirow[t]{2}{*}{.311} \\
\hline Female & $12(60 \%)$ & $15(75 \%)$ & & \\
\hline \multicolumn{5}{|l|}{ Education } \\
\hline Illiterate & $4(20 \%)$ & $6(30 \%)$ & \multirow{4}{*}{2.760} & \multirow{4}{*}{.430} \\
\hline Read \& Write & $14(70 \%)$ & $11(55 \%)$ & & \\
\hline Secondary & $1(5 \%)$ & $3(15 \%)$ & & \\
\hline University & $1(5 \%)$ & $0(0 \%)$ & & \\
\hline \multicolumn{5}{|l|}{ Job } \\
\hline Employee & $4(20 \%)$ & $2(10 \%)$ & \multirow{4}{*}{4.167} & \multirow{4}{*}{.244} \\
\hline Private & $6(30 \%)$ & $3(15 \%)$ & & \\
\hline Housewife & $9(45 \%)$ & $15(75 \%)$ & & \\
\hline Other & $1(5 \%)$ & $0(0 \%)$ & & \\
\hline \multicolumn{5}{|l|}{ Marital status } \\
\hline Married & $16(80 \%)$ & $17(85 \%)$ & \multirow{3}{*}{1.697} & \multirow{3}{*}{.428} \\
\hline Divorced & $0(0 \%)$ & $1(5 \%)$ & & \\
\hline Widow & $4(20 \%)$ & $2(10 \%)$ & & \\
\hline \multicolumn{5}{|c|}{ Treatment method } \\
\hline Private & $18(90 \%)$ & $20(100 \%)$ & \multirow{2}{*}{2.105} & \multirow[t]{2}{*}{.147} \\
\hline Insurance & $2(10 \%)$ & $0(0 \%)$ & & \\
\hline \multicolumn{5}{|l|}{ Residence } \\
\hline Urban & $7(35 \%)$ & $7(35 \%)$ & \multirow[t]{2}{*}{0.0} & \multirow[t]{2}{*}{1.0} \\
\hline Rural & $13(65 \%)$ & $13(65 \%)$ & & \\
\hline \multicolumn{5}{|c|}{ Length of disease } \\
\hline$<3 \mathrm{~m}$ & $8(40 \%)$ & $9(45 \%)$ & \multirow{3}{*}{2.210} & \multirow{3}{*}{.331} \\
\hline $4-8 m$ & $8(40 \%)$ & $4(20 \%)$ & & \\
\hline$>9 m$ & $4(20 \%)$ & $7(35 \%)$ & & \\
\hline \multicolumn{5}{|c|}{ Stage of disease } \\
\hline II & $2(10 \%)$ & $8(40 \%)$ & \multirow{3}{*}{5.100} & \multirow{3}{*}{.078} \\
\hline III & $15(75 \%)$ & $9(45 \%)$ & & \\
\hline IV & $3(15 \%)$ & $3(15 \%)$ & & \\
\hline \multicolumn{5}{|c|}{ Length of treatment } \\
\hline$<3 \mathrm{~m}$ & $19(95 \%)$ & $13(65 \%)$ & \multirow{3}{*}{5.696} & \multirow{3}{*}{.058} \\
\hline $4-8 m$ & $1(5 \%)$ & $6(30 \%)$ & & \\
\hline$>9 m$ & $0(0 \%)$ & $1(5 \%)$ & & \\
\hline
\end{tabular}

Note. $\chi^{2}$ : chi-square test; * significant $(p<.05)$.

On 21st day, $65 \%$ of cryotherapy group free from oral $\mathrm{Mu}-$ cositis (G0) while no one of control group free from OM. As regards G1, it was observed that OM detected at equal rates (35\%) in both cryotherapy \& control group. While G2 \& G3 observed in control group as $45 \%$ \& $20 \%$ respectively) however not found in cryotherapy group. Interestingly, OM (G4) was not detected in both group.

When comparing the effects of cryotherapy on the pain level between cryotherapy and control group at 7 th day according to Table $3 \&$ Figure $2,40 \%$ of cryotherapy group versus no one of control group have no pain at 7 th day of chemotherapy while $60 \%$ of cryotherapy group felt of mild pain compared to $55 \%$ of control group. No one of cryotherapy group experiencing moderate $\&$ sever pain while control group exhibit (40\% \& 5\% respectively). Worst pain was not observed in each group. There was a statistically significant differences in pain development and severity between cryotherapy and control group where $p<.001$. On 14th day, 65\% of cryotherapy group experienced no pain compared to no one of the control group. Similarly $45 \%$ of control group experienced mild pain compared to $35 \%$ in the cryotherapy group. Half of control group patients exhibit moderate pain but nobody in cryotherapy group patient experienced moderate pain. Sever pain was assessed in 5\% of control group but no one in 
cryotherapy group developed sever pain. While worst pain was not determined in either group. So there was a statistically significant differences in pain development and severity between cryotherapy and control group where $p<.001$. On 21 st day, no pain was exhibited by $70 \%$ of cryotherapy group, it was not experienced by any one of control group. However, mild pain was experienced by $40 \%$ of control group compared to $30 \%$ in cryotherapy group. Moderate pain was assessed in $50 \%$ of control group while no one of cryotherapy group exhibit moderate pain. Sever pain experienced only by $10 \%$ of control group, it was not exhibited by cryotherapy group. Worst pain was not experienced in neither group. From these findings it is obvious that ther was a highly statistically significant changes in development and severity of pain between Cryotherapy group and control group at 7th, 14 th $\& 21$ st day where $p<.001$.

Table 3. Pain severity and OM grading according to WHO Mucositis scale for both cryotherapy and control group during the study period

\begin{tabular}{|c|c|c|c|c|c|c|c|c|}
\hline & \multicolumn{2}{|l|}{ 7day } & \multicolumn{2}{|l|}{ 14day } & \multicolumn{2}{|l|}{ 21day } & \multicolumn{2}{|c|}{ Test of significance } \\
\hline & $\begin{array}{l}\text { Cryotherapy } \\
\text { Group } \\
(\mathbf{n}=20)\end{array}$ & $\begin{array}{l}\text { Control } \\
\text { Group } \\
(\mathbf{n}=20)\end{array}$ & $\begin{array}{l}\text { Cryotherapy } \\
\text { Group } \\
(n=20)\end{array}$ & $\begin{array}{l}\text { Control } \\
\text { Group } \\
(\mathbf{n}=20)\end{array}$ & $\begin{array}{l}\text { Cryotherapy } \\
\text { Group } \\
(\mathbf{n}=20)\end{array}$ & $\begin{array}{l}\text { Control } \\
\text { Group } \\
(\mathbf{n}=\mathbf{2 0})\end{array}$ & $\begin{array}{l}\text { Cryotherapy } \\
\text { Group } \\
(\mathbf{n}=20)\end{array}$ & $\begin{array}{l}\text { Control } \\
\text { Group } \\
(\mathbf{n}=20)\end{array}$ \\
\hline \multicolumn{9}{|c|}{ Pain severity } \\
\hline Non & $8(40 \%)$ & $0(0 \%)$ & $13(65 \%)$ & $0(0 \%)$ & $14(70 \%)$ & $0(0 \%)$ & \multirow{7}{*}{$\begin{array}{l}p 1=.059 \\
p 2=.058\end{array}$} & \multirow{7}{*}{$\begin{array}{l}p 1=.157 \\
p 2=.046^{*}\end{array}$} \\
\hline Mild & $12(60 \%)$ & $11(55 \%)$ & $7(35 \%)$ & $9(45 \%)$ & $6(30 \%)$ & $8(40 \%)$ & & \\
\hline Moderate & $0(0 \%)$ & $8(40 \%)$ & $0(0 \%)$ & $10(50 \%)$ & $0(0 \%)$ & $10(50 \%)$ & & \\
\hline Severe & $0(0 \%)$ & $1(5 \%)$ & $0(0 \%)$ & $1(5 \%)$ & $0(0 \%)$ & $2(10 \%)$ & & \\
\hline Worst & $0(0 \%)$ & $0(0 \%)$ & $0(0 \%)$ & $0(0 \%)$ & $0(0 \%)$ & $0(0 \%)$ & & \\
\hline$\chi^{2}$ & 17.043 & & 24.250 & & 26.286 & & & \\
\hline$p$ value & $.001^{*}$ & & $<.001^{* *}$ & & $<.001^{* *}$ & & & \\
\hline \multicolumn{9}{|c|}{ WHO Mucositis grade } \\
\hline 0 & $9(45 \%)$ & $0(0 \%)$ & $11(55 \%)$ & $0(0 \%)$ & $13(65 \%)$ & $0(0 \%)$ & \multirow{7}{*}{$\begin{array}{l}p 1=.414 \\
p 2=.206\end{array}$} & \multirow{7}{*}{$\begin{array}{l}p 1=.083^{*} \\
p 2=.025^{*}\end{array}$} \\
\hline 1 & $11(55 \%)$ & $11(55 \%)$ & $9(45 \%)$ & $8(40 \%)$ & $7(35 \%)$ & 7 (35\%) & & \\
\hline 2 & $0(0 \%)$ & $6(30 \%)$ & $0(0 \%)$ & $9(45 \%)$ & $0(0 \%)$ & $9(45 \%)$ & & \\
\hline 3 & $0(0 \%)$ & $3(15 \%)$ & $0(0 \%)$ & $3(15 \%)$ & $0(0 \%)$ & $4(20 \%)$ & & \\
\hline 4 & $0(0 \%)$ & $0(0 \%)$ & $0(0 \%)$ & $0(0 \%)$ & $0(0 \%)$ & $0(0 \%)$ & & \\
\hline$\chi^{2}$ & 18.0 & & 23.059 & & 26.0 & & & \\
\hline$p$ value & $<.001^{* *}$ & & $<.001^{* *}$ & & $<.001^{* *}$ & & & \\
\hline
\end{tabular}

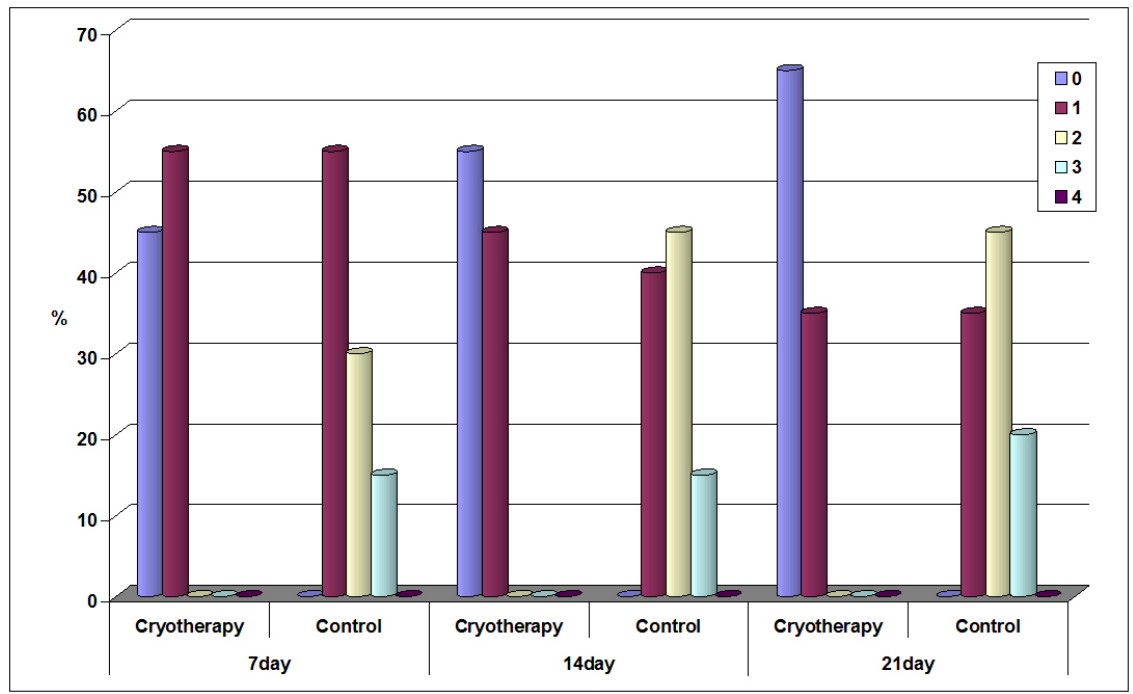

Figure 1. OM grading according to WHO Mucositis scale for both cryotherapy and control group at 7 th, 14 th $\& 21$ st day. $*$ Significant $p<.05$, **Highly significant $p<.001$ 


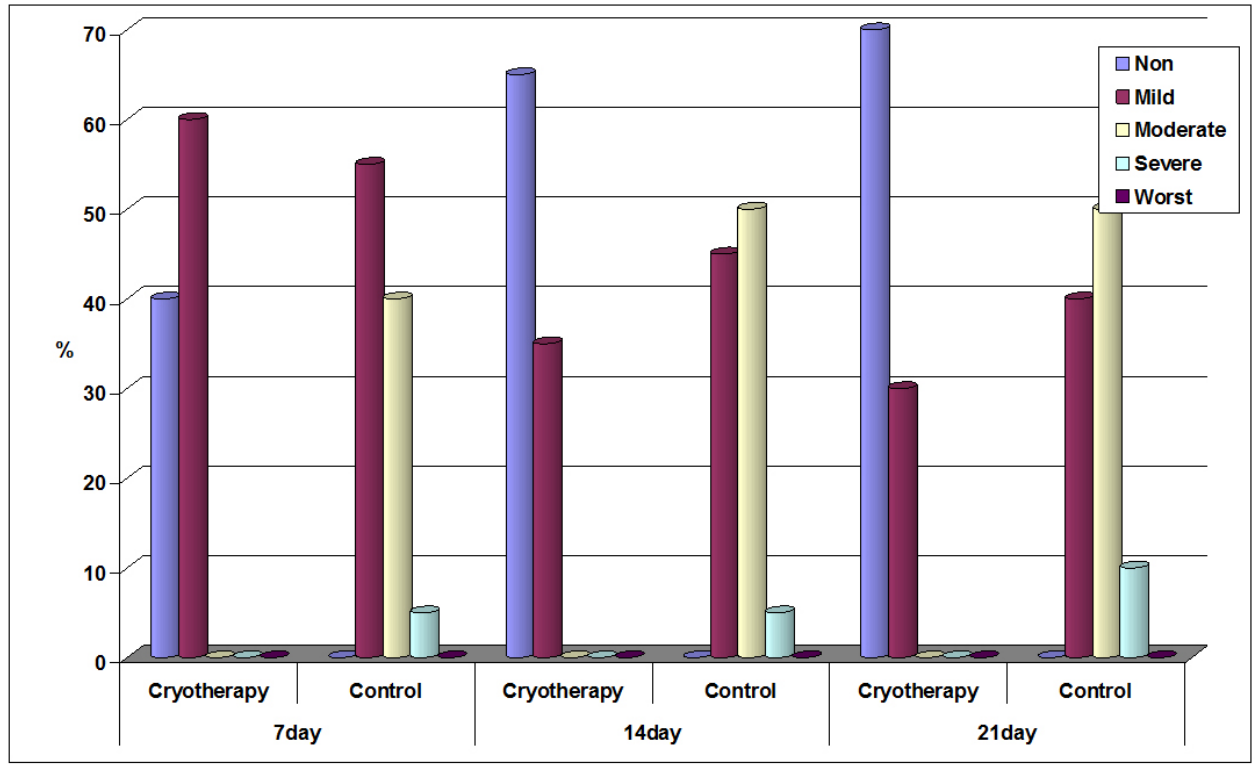

Figure 2. Pain severity for both cryotherapy and control group at 7th, 14th \& 21st day $*$ Significant $p<.05, * *$ Highly significant $p<.001$

Table 4. Patient profile of both cryotherapy and control groups $(n=40)$

\begin{tabular}{lllll}
\hline & $\begin{array}{l}\text { Cryotherapy Group } \\
\text { (n= 20) }\end{array}$ & $\begin{array}{l}\text { Control Group } \\
(\mathbf{n = 2 0 )}\end{array}$ & $\chi^{2}$ & $\boldsymbol{p}$ value \\
\hline Tooth status & $11(55 \%)$ & $12(60 \%)$ & 0.102 & .749 \\
Normal & $0(0 \%)$ & $1(5 \%)$ & 1.026 & .311 \\
Artificial & $1(5 \%)$ & $2(10 \%)$ & 0.360 & .548 \\
Partial implantation & $7(35 \%)$ & $6(30 \%)$ & 0.114 & .736 \\
Tooth loss & $6(30 \%)$ & $6(30 \%)$ & 0.0 & 1.0 \\
Tooth decade & $2(10 \%)$ & $2(10 \%)$ & 0.0 & 1.0 \\
Gum disease & & & & \\
Taste status & $17(85 \%)$ & $12(60 \%)$ & 3.135 & .077 \\
Normal & $3(15 \%)$ & $8(40 \%)$ & & \\
Abnormal & $3(15 \%)$ & $1(5 \%)$ & 1.111 & .292 \\
Visiting dentist & & & & \\
Brushing habit & $7(35 \%)$ & $6(30 \%)$ & 1.563 & .458 \\
One daily & $2(10 \%)$ & $5(25 \%)$ & & \\
More than one daily & $11(55 \%)$ & $9(45 \%)$ & & .292 \\
Never & $3(15 \%)$ & $1(5 \%)$ & 1.111 & .197 \\
Mouth care instructions & $10(50 \%)$ & $14(70 \%)$ & 1.667 & .507 \\
Dry mouth & $12(60 \%)$ & $14(70 \%)$ & 0.440 & \\
Anorexia & & & & \\
Daily water consumption & $6(30 \%)$ & $6(30 \%)$ & 0.0 & 1.0 \\
$<5$ cups & $14(70 \%)$ & $14(70 \%)$ & & .910 \\
$>$ 5cups & $1(5 \%)$ & $0(0 \%)$ & 1.026 & .749 \\
Systemic disease & $2(10 \%)$ & $3(15 \%)$ & 0.229 & .633 \\
HTN & & & & \\
DM & $9(45 \%)$ & $9(45 \%)$ & 0.188 & \\
Bowel habit & $5(25 \%)$ & $7(35 \%)$ & & \\
Normal & $6(30 \%)$ & & & \\
Diarrhea & & & & \\
Constipation & & & & \\
\hline
\end{tabular}




\section{Disscussion}

Mucositis is a crucial adverse effect of cancer treatment that influence persons' quality of life, co morbidity and death rate interestingly, the high price of caring for cancer patient. Different prophylactic agents are examined and suggested to manage these adverse effects. ${ }^{[13]}$ Several studies reported that oral cryotherapy has a useful effect in decreasing development of Mucositis during chemotherapy this may be due to diminished blood flow to oral mucosa as a complication to chemotherapy treatment. The present study indicated that cryotherapy will decrease pain severity and symptoms of Mucositis in patients receiving combined chemotherapy (Fluorouracil and Leucovorin). The purpose of the current study was to evaluate the effect of cryotherapy on incidence and severity of chemotherapy-associated OM and OM related pain in subjects managed by combined chemotherapy (Fluorouracil and Leucovorin). The subsequent research hypothesis developed in an effort to attain the aim of the study: Patients who receive cryotherapy (Cryo group) can have less incidence and severity in $\mathrm{OM}$ and $\mathrm{OM}$ related pain compared to patients who don't receive it (control group).

Discussion of the results is organized in the following sequence: (a) Biosociodemographic characteristics of the sample. b) The impact of cryotherapy on development and severity of $\mathrm{OM}$ associated to chemotherapy and OM releated pain in subject managed by combined chemotherapy (Fluorouracil and Leucovorin).

The results of the current study clarified that there were no statistical significant differences in the sociodemographic data between the cryotherapy group and control groups as regards to age, sex, marital state education, Length of disease and occupation (see Table 1).

There is a strong evidence support that, oral cryotherapy, that is the application of ice cubes on the mouth during the administration of chemotherapy might decrease the development and severity of chemotherapy induced oM. The usage of oral cryotherapy depend upon assumption that ice created vasoconstriction and can decrease oral mucosa blood supply consequently lower local concentration of chemotherapeutic agents. ${ }^{[24]}$ Many studies on patients received 5-FU as a chemotherapeutic agent ascertained that oral cryotherapy reduced formation OM. ${ }^{[20]}$ Due to 5-FU as a chemotherapeutic agent has a short half life about twenty minute, oral cryotherapy for 30-45 minute pre and post administering chemotherapy this might decrease the development of OM. ${ }^{[20]}$

In the current study, after applying cryotherapy a highly statistically significance was noticed between control group and cryotherapy group in incidence and severity of $\mathrm{OM}$ on the 7th 14th and 21 day. Consistent with WHO Mucositis scale, the percentages of Mucositis in the cryotherapy group was $35 \%$ and in control group it was $100 \%$. At the end of the 21 days. In cryotherapy group OM was $55 \%$ after 7 day \& changed to $35 \%$ grade (1) at 21 day (i.e., Mucositis risk was reduced at the end of the study). When compared to control group, OM was $100 \%$ at the 7 th day, as well as, the rate of grade 3 Mucositis was $15 \%$ in day 7 th changed to $20 \%$ in day 21. In control group according to WHO Mucositis grades, it was found that no fourth-grade was detected. The findings of the present study confirmed that there was a extremely statistically significant variations in incidence and severity of OM between cryotherapy group and control group on 7th, 14th and 21days where $p<.001$. This result supported by Karagozogulu $^{[35]}$ who study effectiveness of oral cryotherapy on the development of chemotherapy associated OM. Cryotherapy was started 5 minutes pre chemotherapy \& continued during infusion of chemotherapeutic agents. The patients were evaluated at the end of first course using a patient judged Mucositis grading and physician judged mucositis grading.

Based on patient reported mucositis grade, the percentage of mucositis in study group was $36.7 \%$ and in control group it was $90 \%$. As regards physician judged mucositis scale, the percentage of mucositis in cryo group was $10 \%$ and in control group it was 50\%. This therapy has a significant effect on reducing $\mathrm{OM}$ associated with infusion of 5-fluorouracil with leukovorine. In line with Karagozoglu et al. and Papadeas et al., ${ }^{[21,22]}$ they found that oral cryotherapy considerably reduced the severity and incidence of mucositis related chemotherapy. Interestingly Svanberg findings indicated that participants who apply oral ice chips had less formation of stomatitis, minimized use of i.v. opioids, reduced hospitalization time, need for fewer total parenteral nutrition and elevated levels of S-albumin. ${ }^{[11,36]}$ In a totally different study carried out in Turkey while Mucositis developed in $6.7 \%$ in experimental group (cryotherapy group), this ratio was $38.9 \%$ in control group. Several research studies evaluating the impact of cryotherapy have clarified that it has positive effect on reducing development of OM among subjects treated by chemotherapy ${ }^{[7]}$ in going with this result. ${ }^{[14]}$

Basically, following chemotherapy Mucositis developed at 5-10 days or at 7-14 days which parallel to suppression of immune system because of reduce number of white blood cells, interestingly, the development of OM increase on seventh, 14 th and continue to 21 st day. ${ }^{[21]}$

The current study showed that there have been statistically significant differences between cryotherapy and control group related to pain incidence and severity at two times interval (seventh day \& 21st) day of chemotherapy, where $p=.046$. This finding of the study was along with Cooper 
and Dawber ${ }^{[38]}$ who identified that Oral cryotherapy has been shown to be effective in preventing and/or reducing the severity of OM when used with patients receiving certain chemotherapy regimens or radiotherapy additionally tissue cooling has traditionally been used to relieve both acute and chronic pain. ${ }^{[39,40]}$ Other results of Cancer Net Editorial Board $^{[41]}$ showed that cooling of the oral mucosa reduced the development of OM and alleviated oral pain. Study done by Kakoei et al., clarified that cryotherapy effective in minimizing pain and other mucositis symptoms in subjects with head and neck cancer, receiving radiotherapy. Increase pain level in the control group was statistically significant $(p<$ .01 ), interestingly no changes were detected in the experimental group $(p=.155) .{ }^{[39]}$ This findings congruent with Kakoei et al. ${ }^{[15]}$ who clarified that cryotherapy effective in minimizing pain and other mucositis symptoms in subjects with head and neck cancer, receiving radiotherapy. Other research conducted on sixty subjects evaluated the impact of cryotherapy on OM among subjects undergoing chemotherapy. The finding were similar to the current findings, severity of mucositis in cryo group were significantly less than that in the control group. ${ }^{[42]}$

Dodd study evaluates risk factors of OM \& discovered that OM developed in patients with inadequate oral hygiene. ${ }^{[43]}$ Therefore, Dodd supported that poor oral hygiene was probably one cause of mucositis.

Different research studies stressed the importance of reducing patient risk factors by enhancing life style (healthy diet daily oral hygiene, periodic teeth evaluation and treating dental problems) to prevent OM during cancer therapy. ${ }^{[44]}$ In the present study about half of the studied sample did not routinely brush their teeth and only $15 \%$ of cryotherapy group visiting dentist before taking chemotherapy and take mouth care instructions. Therefore these factors had a negative impact on oral mucosa and Mucositis was expected. The nurse have a pivotal role in evaluating, improving patients knowledge and practice regarding oral hygiene to prevent incidence of this problem. This might be accomplished by regular daily evaluation of Mucositis and regular teaching by the nurse may have lead to improve awareness and resulted in eliminate incidence of Mucositis. ${ }^{[19]}$

\section{Conclusion}

The researchers discovered that oral cryotherapy has a prominent effects in decreasing mucositis score based on the WHO mucositis grade, particularly on the 7th and 14th and 21st days. Additionally, patients in cryotherapy group tolerated the cryotherapy management quite well. Confirming that this methods can be easily applied due to its effectiveness in reducing incidence and severity of OM. Because of its easy administration, bearable, and lack of adverse effects, oral cryotherapy is suggested in preventing and reducing the severity of OM. This findings come consistent with the [Multinational Association of Supportive Care in Cancer (MASCC) guidelines]. ${ }^{[3]}$ Cryotherapy can be recommended as safe, cheap, applicable methods for preventing OM among cancer subjects receiving chemotherapy

\subsection{Limitations of the study}

- People who are in the age group of more than 20 years to 60 years diagnosed of colon, rectal and gastric cancer.

- Who are receiving combined chemotherapy (Fluorouracil and Leucovorin) in selected oncology hospital.

- Small sample size.

\subsection{Relevance to clinical practice}

Oncology nurses should prioritize the prevention of OM by applying oral cryotherapy for patients treating with chemotherapeutic agents. Nurses' awareness about the effect of cryotherapy can affect options for managing problems and will enable them to institute standardized measures. In Egypt further research studies are recommended because of a limited number of related studies. Additionally, other investigator nurse to carry out a well established research with sufficiently big study sample size to evaluate the impact of oral ice ships on OM in more recent chemotherapeutic treatments.

\section{ACKNOWLEDGEMENTS}

I would like to extend my sincerest gratitude and appreciation to my husband and children, who were the driving force in this work, give me so much energy and love. I would like to express my thanks to Oncology Department Director, Mansoura University Hospital and Director of Mitghamer Oncology Center, for their assistance. Also express my gratitude to the nursing staff at two settings. With particular appreciation to Mrs. Hassan for help with the statistical consultant in the present study. Special thanks to participating patients and staff.

\section{CONFLicts OF InTEREST Disclosure}

There is no conflict of interest in this study. 


\section{REFERENCES}

[1] Harris DJ, Eilers J, Harriman A. Putting evidence into practice: Evidence-based interventions for the management of oral ucositis. Clin J Oncol Nurs. 2008; 12(1): 141-52. PMid:18258584 https://doi.org/10.1188/08.CJON.141-152

[2] Rodriguez-Caballero A, Torres-Lagares D, Robles-Garcia M, et al. Cancer treatment-induced oral ucositis: a critical review. Int J Oral Maxillofac Surg. 2012; 41: 225-38. PMid:22071451 https: //doi.org/10.1016/j.ijom.2011.10.011

[3] Worthington HV, Clarkson JE, Bryan G, et al. Interventions for preventing oral ucositis for patients with cancer receiving treatment. Cochrane Database Syst Rev. 2011.

[4] Ridge JA, Glisson BS, Lango MN. Head and Neck Tumors.In: Cancer Management: A Multidisciplinary Approach, (Pazdur R, Wagman LD, Camphausen KA, Hoskins WJ, eds.). 11 ed. 2008.

[5] Sonis ST, Elting LS, Keefe D, et al. Perspectives on cancer therapyinduced mucosal injury: pathogenesis, measurement, epidemiology, and consequences for patients. Cancer. 2004; 100: 1995-2025. PMid:15108222 https://doi.org/10.1002/cncr. 20162

[6] Hernández-Fernández A, Oñate-Sánchez RE, Cabrerizo-Merino $\mathrm{MC}$, et al. Influence of oral health on ucositis in patients undergoing hematopoietic progenitor cell transplantation (HPCT). Med Oral Patol Oral Cir Bucal. 2012; 17: e94-e101. PMid:22157660 https://doi.org/10.4317/medoral.16997

[7] Peterson DE, Bensadoun RJ, Roila F. Management of oral and gastrointestinal ucositis: ESMO Clinical Practice Guidelines. Annals of Oncology. 2010; 21(Supplement 5): v261-v5. PMid:20555094 https://doi.org/10.1093/annonc/mdq197

[8] López-Castaño F, Oñate-Sánchez RE, Roldán-Chicano R, et al. Measurement of secondary ucositis to oncohematologic treatment by means of different scale. Review. Med Oral Patol Oral Cir Bucal. 2005; 10: 412-21.

[9] Peterson DE, Ohrn K, Bowen J, et al. For the Mucositis Study Group of the Multinational Association of Supportive Care in Cancer/International Society of Oral Oncology (MASCC/ISOO). Systematic review of oral ucositis y for management of oral ucositis caused by cancer therapy. Support Care Cancer. 2012. PMid:22993025 https ://doi.org/10.1007/s00520-012-1562-0

[10] Worthington HV, Clarkson JE, Eden OB. Interventions for preventing oral ucositis for patients with cancer receiving treatment. Cochrane Database Syst Rev. 2007; CD000978. https ://doi .org/10.100 2/14651858. CD000978. pub3

[11] Svanberg A, Ohrn K, Birgegard G. Oral ucositis y reduces ucositis and improves nutrition - a ucositis controlled trial. Journal of Clinical Nursing. 2010; 19: 2146-51. PMid:20659194 https: //doi.org/10.1111/j.1365-2702.2010.03255.x

[12] Heydari A, Sharifi H, Salek R. Effect of Oral Cryotherapy on Combination Chemotherapy-induced Oral Mucositis: A Randomized Clinical Trial. Middle East Journal of Cancer. 2012; 3(2 \& 3): 55-64.

[13] Worthington HV, Clarkson JE. Prevention of oral mucosis and oral candidiasis for patients with cancer treated with chemotherapy: Cochrane systemic review. J Dent Educ. 2002; 66: 903-11.

[14] katraci N, Ovayolu N, Ovayolu $\mathrm{O}$, et al. evaluation the effect of Cryotherapy in preventing oral - a randomized controlled trial. European Journal of Oncology Nursing. 2012; 16: 339-344. PMid:21911313 https://doi.org/10.1016/j.ejon. 2011.07 .008

[15] Kakoei S, Ghassemi A, Nakhaee N. Effect of cryotherapy on oral mucositis in patients with head and neck cancers receiving radiotherapy. Int. J. Radiat. Res. April 2013; 11(2): 117-120.

[16] Worthington HV, Clarkson JE, Eden OB. Interventions for preventing oral mucositis for patients with cancer receiving treatment. Cochrane
Database Syst Rev. 2006. https : //doi .org/10.1002/14651858 .CD000978.pub2

[17] Sideras K, Loprinzi CL, Foote RL. Oral Complications In: Abeloff MD, Armitage JO, Niederhuber JE, Kastan MB, editors. Abeloff's clinical oncology, 4th ed.Philadelphia: Churchill Livingstone/Elsevier; 2008.

[18] Nikoletti S, Hyde S, Shaw T, et al. Comparison of plain ice and flavoured ice for preventing oral ucositis associated with the use of 5 fluorouracil. Journal of Clinical Nursing. 2005; 14: 750-3. PMid:15946283 https ://doi.org/10.1111/j.1365-2702.20 05.01156.x

[19] Bhatt V, Vendrell N, Naukcrumb D, et al. Implementation of a standardized protocol for preventopn and management of oral Mucositis in patients undergoing hematopoietic cell transplantation. Journal of Oncology Pharmacy Practice. 2010; 16: 195-204. PMid:19910393 https://doi .org/10.1177/1078155209348721

[20] Sorensen JBT, Skovsgaard TE, Damstrup L, et al. Double-blind, Placepo controlled, randomized study of chlorhexidine prophylaxis for 5-fluorouracil-based chemotherapy-induced oral Mucositis with nonblinded randomized comparison to oral cooling (Cryotherapy) in gastrointestinal malignancies. Cancer. 2008; 112: 1600-1606. PMid:18300265 https://doi.org/10.1002/cncr. 23328

[21] Karagozoglu S, Ulusoy M. Chemotherapy: The effect of oral ucositis $y$ on the development of ucositis. Journal of Clinical Nursing. 2005; 14(6): 754-65. PMid:15946284 https://doi.org/10.111 $1 / j .1365-2702.2005 .01128 \cdot x$

[22] Papadeas E, Naxakis S, Riga M, et al. Prevention of 5-fluorouracilrelated stomatitis by oral ucositis y: A randomized controlled study. European Journal of Oncology Nursing. 2007; 11(1): 60-5. PMid:16829196 https://doi.org/10.1016/j.ejon.2006.05 .002

[23] World Health Organization. Handbook for reporting results of cancer treatment. Geneva: WHO. 1979; 15-22.

[24] Gori E, Arpinati M, Bonifazi F. Cryotherapy in the prevention of oral mucositis in patients receiving lowdose methotrexate following myeloablative allogeneic stem cell transplantation: A prospective randomized study of the Gruppo Italiano Trapianto di Midollo Osseo nurses group. Bone Marrow Transplantation. 2007; 39: 347-52. PMid:17277790 https://doi .org/10.1038/sj . bmt. 1705590

[25] Celkan T. Kanser cocukozit.klink gelism. 2007; 20: 195-198.

[26] Cavusoglu H. Oralmukozit yonetiminde Kanta dayali hemsirelik. Turkiye klinikler Journal of Medical Science. 2007; 27: 398-406.

[27] Fejer R, Jordan A, Hartvigsen J. Categorising the severity of neck pain: establishment of cut points for use in clinical and epidemiological research. Pain. 2005; 119: 176-82. PMid:16298059 https : //doi.org/10.1016/j.pain.2005.09.033

[28] Jensen MP, Smith DG, Ehde DM, et al. Pain site and the effects of amputation pain: further clarification of the meaning of mild, moderate, and severe pain. Pain. 2001; 91: 317-322. https : //doi.org/10.1016/S0304-3959(00)00459-0

[29] Paul SM, Zelman DC, Smith M, et al. Categorizing the severity of cancer pain: further exploration of the establishment of cutpoints. Pain. 2005; 113: 37-44. PMid:15621362 https://doi.org/10.1 016/j.pain. 2004.09.014

[30] Serlin RC, Mendoza TR, Nakamura Y, et al. When is cancer pain mild, moderate or severe? Grading pain severity by its interference with function. Pain. 1995; 61: 277-284. https://doi.org/10.1 016/0304-3959 (94) 00178-H

[31] Turner JA, Franklin G, Heagerty PJ, et al. The association between pain and disability. Pain. 2004; 112: 307-314. PMid:15561386 https://doi.org/10.1016/j.pain.2004.09.010

Published by Sciedu Press 
[32] Zelman DC, Dukes E, Brandenburg N, et al. Identification of cutpoints for mild, moderate and severe pain due to diabetic peripheral neuropathy. Pain. 2005; 115: 29-36. PMid:15836967 https : //doi.org/10.1016/j.pain.2005.01.028

[33] Migliorati CA, Oberle-Edwards L, Schubert M. The role of alternative and natural agents, cryotherapy, and/or laser for management of alimentary mucositis. Supportive Care in Cancer. 2006; 14: 533-40. PMid:16572313 https://doi.org/10.1007/s00520-006-004 9-2

[34] Mohamadian H, Eftekhar H, Rahimi A, et al. Predicting health-related quality of life by using a health promotion model among Iranian adolescent girls: A structural equation modeling approach. Nurs Health Sci. 2011; 13: 141-8. PMid:21595808 https : //doi.org/10.111 $1 / j .1442-2018.2011 .00591 . x$

[35] Serife Karagozogulu. Chemotherapy: the effect of oral cryotherapy on the development of oral mucositis. Journal of clinical Nursing. 2005; (14): 754-763. PMid:15946284 https ://doi.org/10.111 $1 / \mathrm{j} .1365-2702.2005 .01128 . \mathrm{x}$

[36] Svanberg A, Birgegård G, Öhrn K. Oral cryotherapyreduces mucositis and opioid use after myeloablative therapy-a randomized controlled trial. Support Care Cancer. 2007; 15: 1155-61. PMid:17393189 https://doi .org/10.1007/s00520-007-024 5-8

[37] Aisa Y, Mori T, Kudo M, et al. Oral Cryotherapy for the prevention of high-dose melphalan-induced stomatitis in allogenec hematopoitec stem cell transplant recipients. Suppotive Care in Cancer. 2005;
13: 266-269. PMid:15668755 https://doi.org/10.1007/s005 20-004-0726-y

[38] Cooper SM, Dawber RPR. The history of cryosurgery. J R Soc Med. 2001; 94(4): 196-201. PMid:11317629 https://doi.org/10.1 $177 / 014107680109400416$

[39] Farah, CS. and Savage, NW. Cryotherapy for treatment of oral lesions, Aus Dent J. 2006; 51(1): 2-5. PMid:16669469 https: //doi.org/10.1111/j.1834-7819.2006.tb00392.x

[40] Svanberg AO, Hrn K, Birgegard G. Unexpected 5 year survival benefit in patients given oral cryotherapy during conditioning for stem cell transplantation. A prospective randomized study. Blood. 2011.

[41] Cancer Net Editorial Board. Head and Neck Cancer: Risk Factors and Prevention. 2014. Available from: http: //www. cancer.net/cancer-types/head-and-nec $\mathrm{k}$-cancer/risk-factors-andprevention

[42] Karagozoglu S, Filiz M. Chemotherapy: the effect of oral cryotherapy on the development of mucosis. J Clin Nurs. 2005; 14: 656-754. https://doi.org/10.1016/j.reaurg. 2005.10.024

[43] Dodd MJ, Miaskowski C, Shiba GH, et al. Risk factors for chemotherapy-induced oral mucositis: Dental appliances, oral hygiene, previous oral lesions, and history of smoking. Cancer Invest. 1999; 17(4): 278-84. PMid:10225008 https ://doi .org/10.310 9/07357909909040598

[44] Yilmaz MC. Evidence-based practices for managing Mucositis. International Journal of Hematology and Oncology. 2007; 4: 241-246. 